\title{
Ruptures of Prepubic Tendon in Shami (Damascus) Breed Pregnant Goats
}

\author{
Al-Ani FK ${ }^{1}$ and Khamas W ${ }^{2}$ \\ ${ }^{1}$ Biology Section, College of Applied Sciences, A'Sharqiyah University, Sultanate of Oman \\ ${ }^{2}$ College of Veterinary Medicine, Western University of Health Sciences, Pomona, CA, USA
}

Corresponding author: Khamas W, College of Veterinary Medicine, Western University of Health Sciences, Pomona, CA, USA, Tel: 001909-469-5526; E-mail: wkhamas@westernu.edu

Received: Jun 17, 2016; Accepted: Jun 28, 2016; Published: Jun 30, 2016

Citation: Al-Ani FK, Khamas W. Ruptures of Prepubic Tendon in Shami (Damascus) Breed Pregnant Goats. Transl Biomed. $2016,7: 2$.

\section{Abstract}

Background: The prepubic tendon is the tendon of insertion of abdominal in addition to the gracilis and the pectineus muscles attachment site. Rupture of the prepubic tendon was described in several animal species. However, surgical intervention was not recommended due to cost prohibition and the possibility of unsuccessful result.

Methods and findings: Three pregnant does with prepubic tendon rupture were diagnosed in Shami breed goats during the last month of pregnancy. Clinical examination revealed normal parameters in the three does with no signs of herniation in the abdominal wall.

The does were treated surgically and cesarean sections (CS) were performed to deliver the kids because of the distension of the abdomen and the difficulty to have them go through normal delivery process. Three fetuses in one doe and two in each of the other two were successfully pulled alive from apparently normal uteri.

Conclusion: All does survived the operations and recovered uneventfully but the prepubic tendon was not fixed. All goats were dismissed from the hospital 2- 3 days post-surgery. Unfortunately, no follow up was possible because the owners took them home and did not report back to the clinical center. Preventing stress, trauma and selecting for does that less probably produce quadruplets will decrease the chance of the prepubic tendon rupture.

Keywords: Goat; Prepubic tendon rupture; Shami breed; Jordan

\section{Introduction}

The prepubic tendon is a flat T-shaped compound tendon that provides attachment for the gracilis, pectineal and several abdominal muscles (Figure 1). As the abdomen bulges ventrally in ruminant, the prepubic tendon extends ventrally from the brim of the pelvis at almost right angle with the pelvic floor [1]. Prepubic tendon is composed of crossed and uncrossed tendons of origin of the pectineus muscles, the pelvic tendons of the rectus and obliquus abdominis muscles, and the tendons of origin of the cranial parts of the gracilis muscles [2].

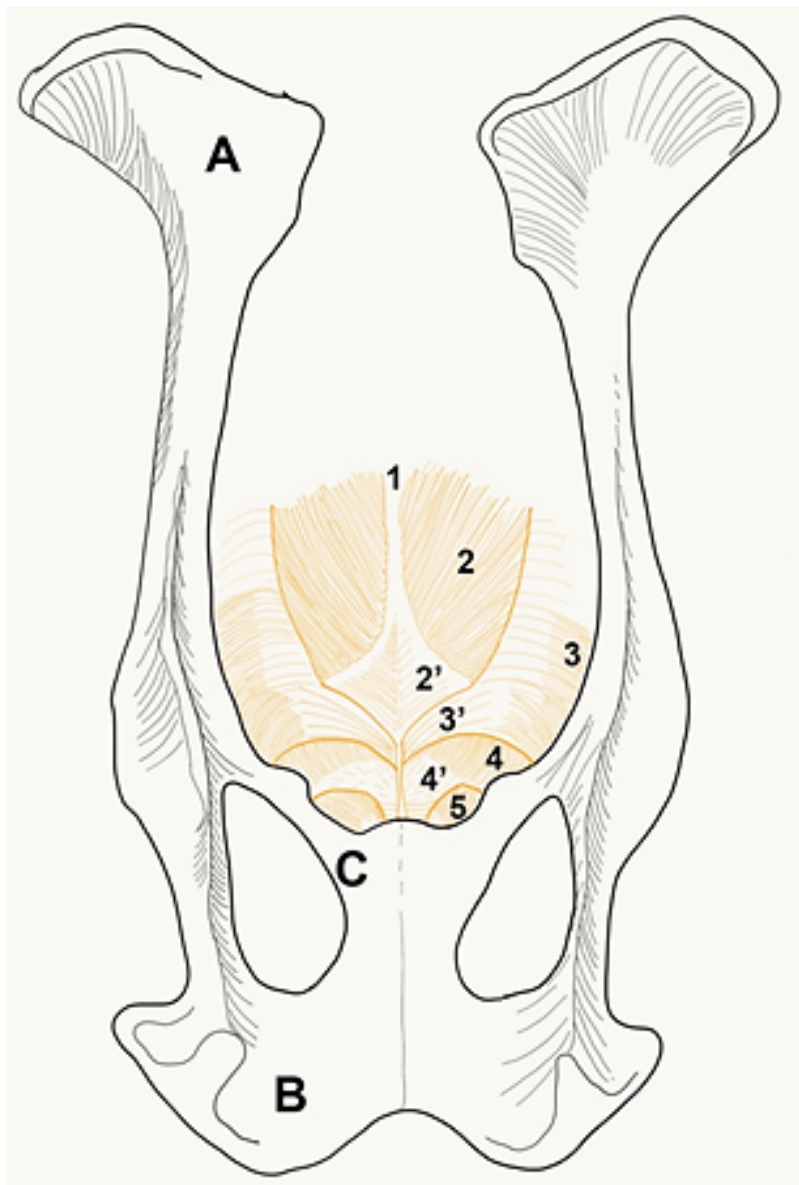

Figure 1 Dorsal view of the caprine pelvis to describe the prepubic tendon. A: ilium; B: ischium; C: pubis; 1 : linea alba; 2 : rectus abdominis muscle; $2^{\prime}$ : terminal tendon of $2 ; 3$ : internal abdominal oblique muscle; $3^{\prime}$ : caudal portion of the aponeurosis of 3; 4: external abdominal oblique muscle; 4': caudal portion of the aponeurosis of 4 . Prepubic tendon would be comprised by 2', 3', 4' and 5 . pectineus muscle. 
Aleem et al. [3] described a case of prepubic tendon rupture in one Beetal goat where three live kids were removed by CS. In ruminants, the prepubic tendon is more or less the same as in equine in respect to the two recti muscles contribution. The ventral surface of the prepubic tendon also provides the origin for the symphyseal tendon in ruminant (well developed in female), which furnishes attachment to the obliquus externus abdominis as well as to the gracilis and pectineus [4]. In dog, the transverse fibers predominate because the rectus abdominis continues as a fleshy muscle to its termination [5]. Pelvic attachment of the linea alba and the tunica flava are incorporated in the prepubic tendon [2]. The tendon may be ruptured in late pregnancy in mares [6-8]. Rupture of prepubic tendon due to hydroallantois was reported in a goat [9] and in a nine-year old bitch [10]. However, the condition is rarely reported in cattle and buffalo in which the rupture is usually cranial to the prepubic tendon in the abdominal muscles $[11,12]$. Rupture of the prepubic tendon in three pregnant Shami (Damascus) breed goats is described in this paper. The terms Shami and Damascus were used interchangeably in the literature to indicate the same breed of goats. For the sake of convenience Shami breed will be used thought out the text of this study.

\section{Materials and Methods}

Three multiparous pregnant does of the Shami breed were referred to the Veterinary Health Center, Faculty of Veterinary Medicine, Jordan University of Science and Technology, with complaint of abnormal abdominal distension during the last month of pregnancy. A complete history was recorded. The goats were subjected to routine clinical examination, and due to the difficulty of normal delivery CS were performed to deliver the fetuses alive.

\section{Results}

The main clinical finding was the distension of the ventral abdominal wall with an area of edema involving the ventral abdominal wall. The edematous area extended from the umbilical region to the udder (Figure 2). Udder edema was excluded as the udder was clinically normal. The goats were in the last month of pregnancy and the udders contained colostrum extending ventrally bilaterally to the level of the ground. Despite the presence of severe edema, the general contour of the abdominal floor was normal and no defects were palpable which exclude ventral abdominal wall herniation. All of the three goats were emaciated and were reported to have low appetite. No other abnormalities were detected in the gastrointestinal tracts. The body temperature and respiratory rate were within normal ranges while the pulse rates were elevated in all three does.

Caesarean sections revealed the presence of three fetuses in one doe and two fetuses in each of the other two does within apparently normal uteri. The abdominal floor was normal and no hernia was detected. The three does survived the surgeries and recovered from anesthesia uneventfully.

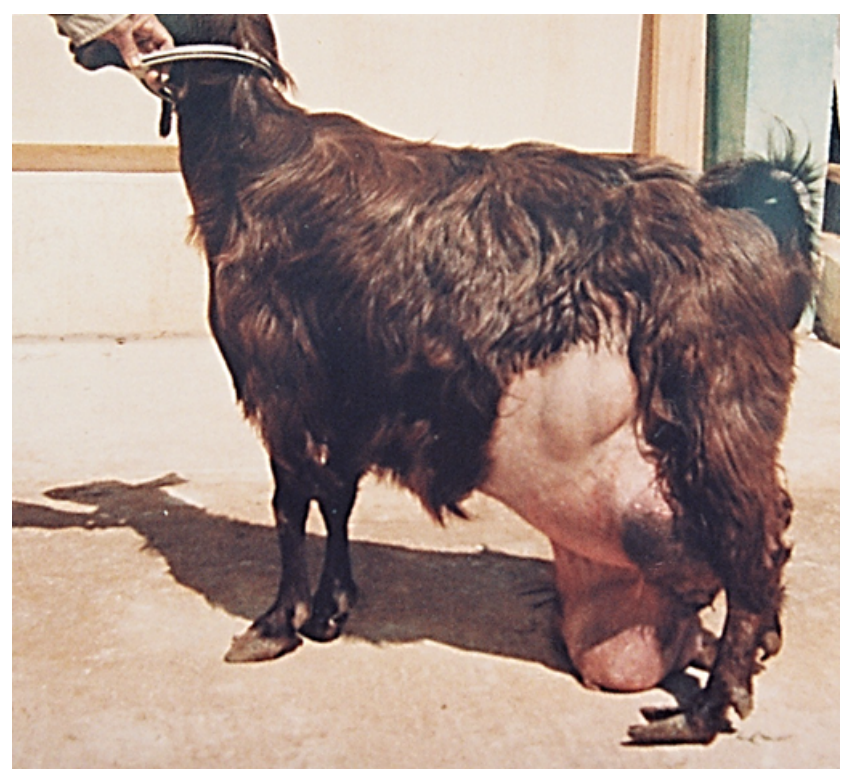

Figure 2 Adult pregnant Shami breed doe with rupture of the prepubic tendon. Notice the mammary glands were dropped on the ground which exposes the animal to injury and possible infection.

\section{Discussion}

The prepubic tendon has the form of a very strong thick band with concave lateral borders which, in turn, form the medial boundaries of the superficial inguinal rings. The obliquity of the tendon and the angles, which it forms with pelvic floor are of clinical importance in obstetrical cases. However, the slope varies in different animal species [4]. The prepubic tendon of the ruminant has been described to be attached to the pelvis by three roots in the median symphyseal tendon and two thick lateral roots, which are attached to the iliopectineal (iliopubic) eminences. Habel and Budras [2] stated that the lateral root can be visualized as similar to the equine accessory ligaments of the femur, while, the caudal end of the linea alba is incorporated in the prepubic tendon in ungulates. The fact that rupture of the PT in pregnant cows is rare in comparison to the mare may be attributed to the added support provided by the symphyseal tendon, which is longer in the cow and more firmly attached to the external surface of the prepubic tendon by its continuity with the tendon of the recti, graciles and the abdominal tendon of the external obliquus muscle [2]. Rupture of the prepubic tendon results in loss of the ventral girdle support of the animal's abdomen [7]. The cause of the rupture is uncertain, however; in mares the condition is generally associated with hydroallantois, twin pregnancy and trauma to the mare during late gestation $[8,9,13]$. Herniation has been reported in dogs and buffalos by several investigators $[14,15]$ In small ruminants, rupture of the prepubic tendon is more complicated as it usually leads to injury of the udder due to the closeness of the udder to the ground because of the animal heights, which results in major complications if not treated immediately. This condition has 
been seen more frequently in Shami breed does which are dual purpose goats $[16,17]$ with their relatively high reported birth weight of $3.5-5.5 \mathrm{Kg}$. Pugh [18] stated that rupture of the prepubic tendon is occasionally seen in sheep and goats pregnant with multiple fetuses (polytocus animals), pregnant with fetal hydrops, and pregnant females that have experienced abdominal trauma. Furthermore, it has been reported that total milk production in Shami breed goats ranges between 350-650 kg/goat/lactation [19]. Correlation between genetic factors and milk production were reported in the same breed in Cyprus [15]. Also, a hereditary tendency for various types of congenital anomalies in Shami breed goats has been reported [20]. In spite of the recommendation of other researchers that these does should be culled after cesarean section due to prepubic tendon rupture because of the possibility that it may recur in the next pregnancy, the owners of these goats requested that we did the CS and keep the dams alive. The affected goats were effectively cured following surgery though the prepubic tendon was not fixed. All goats were dismissed from the hospital 2 to 3 days postsurgery. Unfortunately, no follow up was possible because the owners took them home and did not report to the clinical center to check on their future pregnancies and health

Therefore, Shami breed goats with high birth weight, twins and frequent triplets in addition to the mammary glands weight will predispose this breed to prepubic tendon rupture compared to other species and breeds. Unreported or undiagnosed prepubic tendon rupture in this species are expected to be high and any additional report may shed a light on this anatomical defect and their future abilities to be pregnant.

\section{Acknowledgement}

Figure 1 diagram and labeling was kindly prepared by Dr. J. Rutllant, professor of anatomy and embryology/College of Veterinary Medicine, Western University of Health Sciences, Pomona, CA, USA.

\section{References}

Habel RE (1989) Guide to the dissection of domestic ruminants. ( $1^{\text {st }}$ edn) 1529 Ellis hollow road, Ithaca, New York, USA pp: 81-83.

Habel RE, Budras KD (1992) Anatomy of the prepubic tendon in the horse, cow, sheep, goat and dog. Am J Vet Res 53: 2183-2195.

Aleem M, Ijaz A, Khan M (2010) Rupture of the prepubic tendon in a beetal goat. Ind Vet J 87: 63-64.
Getty R (1975) Sisson and Grossman's: The anatomy of the domestic animals. ( $1^{\text {st }}$ edn). W.B. Saunders co., Philadelphia, USA, 412 and pp: 821.

de Lahunta A, Habel R (1986) Applied veterinary anatomy. Second Ed, W.B. Saunders co., Philadelphia, USA pp: 223.

Jackson PG (1982) Rupture of the prepubic tendon in shire mare. Vet Rec 111: 38

Hanson RR, Todhunter RJ (1986) Herniation of the abdominal wall in pregnant mares. JAVMA. 189: 790-793.

Ley WB (1994) Management of the foaling mare: prefoaling considerations. Vet Med 559-569.

Selvaraju LK, Ravikumar M, Palanisamy V, Prabaharan E, Napolean R, et al. (2010) Rupture of prepubic tendon due to hydroallantois in a goat. J Vet Anim Sci 41: 6455.

10. Green SR, Quigg JA, Holt PE (1989) Vesicocutaneous fistulation following prepubic tendon rupture in a bitch. J Small Anim Pract 30: 315-317.

1. Emmerson MA (1944) Rupture of the prebubian and subpubian tendons in the cow. University of Pennsylvania. Vet Ext 94: 3-15.

Pycock JF (2003) Late term pregnancy problems in the mare: ventral ruptures. UK Vet 8: 15.

Waldron DR, Hedlund CS, Pechman R (1986) Abdominal hernias in dogs and cats: a review of 24 cases. J Am Anim Hosp Assoc 22: 817-823.

14. Sharma SN, Prasad B, Kohli RN (1980) Surgical repair of unilateral prepubic tendon rupture in a she-buffalo. Indian Vet J 57: $249-250$

5. Shaw SP, Rozanski EA, Rush JE (2003) Traumatic body wall herniation in 36 dogs and cats. J Am Anim Hosp Assoc 39: 3545.

16. Mavrogenis AP, Papachristoforou C (2000) Genetic and phenotypic relationships between milk production and body weight in chios sheep and Damascus goats. Livestock Prod Science 67: 81-87.

Mavrogenis A, Antoniades N, Hooper R (2006) The Damascus (Shami) goat of Cyprus. Agri 38: 57-65.

Pugh DG (2002) Sheep and goat medicine, Saunders, an imprint of Elsevier, The Curtis center, independence square west, Philadelphia, Pennsylvania, 19006, USA pp: 166.

Louca A, Mavogenenis A, Lawler M (1975) The effect of early weaning on the lactation performance of Damascus goats and the growth rate of the kids. Animal Prod 20: 213-218.

Al-Ani FK, Khamas WA, Al-Qudah KM, Al-Rawashdeh O (1998) Occurrence of congenital anomalies in Shami breed goats: 211 cases investigated in 19 herds. Small Rum Res 28: 225-232. 